\title{
ARTIGO
}

\section{Por uma Pesquisa Histórica Comparada entre Museus Históricos Regionais - Ceará/Goiás}

\author{
For a Comparative Historical Research between Regional \\ Historical Museums - Ceará/Goiás
}

\author{
Daniel Barreto Lopes \\ Mestre em Preservação do Patrimônio Cultural - PEP/MP/IPHAN \\ danielblopes18@gmail.com
}

\begin{abstract}
RESUMO: O objetivo do presente trabalho é discutir notas de pesquisa sobre a atribuição de valor histórico a museus históricos regionais, identificando espaços distintos que narram, expõem e visibilizam vestígios do passado a partir da constituição de acervos. $\mathrm{O}$ artigo traz como objeto de estudo o Museu Regional dos Inhamuns, no Ceará, e o Museu Couros de Formosa, em Goiás, correlacionados dentro de um recorte temporal a partir da instituição de seus respectivos espaços museológicos na década de 1990. Referente a metodologia de história comparada aplicada ao campo da escrita da história nos museus, percebemos como as instituições museais produzem uma narrativa com tais materiais e constroem memórias com eles, valorizados como autênticos fragmentos do passado e perpetuação de uma tradição local por meio dos objetos. Por fim é demonstrado distanciamentos e aproximações entre os dois museus históricos pesquisados a partir de suas respectivas museografias.
\end{abstract}

PALAVRAS-CHAVE: Museus. Identidades. Memória.

ABSTRACT: The objective of the present work is to discuss research notes on the attribution of historical value to regional historical museums, identifying distinct spaces that narrate, expose and show traces of the past from the constitution of collections. The article has as object of study the Regional Museum of Inhamuns, in Ceará, and the Museum Couros de Formosa, in Goiás, correlated within a time frame from the institution of their respective museum spaces in the 1990s. comparative history applied to the field of history writing in museums, we perceive how museum institutions produce a narrative with such materials and build memories with them, valued as authentic fragments of the past and perpetuation of a local tradition through objects. Finally, distances and approximations between the two historical museums surveyed are demonstrated from their respective museographies.

KEYWORDS: Museums. Identities. Memory. 


\title{
Introdução
}

Como formas de narrar, expor e dar visibilidade ao passado, os museus são instituídos como lugares apropriados para se preservar objetos "testemunhos" das tradições de uma determinada cultura.

Assim, o objetivo do presente trabalho é discutir notas de pesquisa sobre a atribuição de valor histórico a museus históricos regionais, identificando como esses espaços museológicos narram, expõem e visibilizam vestígios do passado a partir da constituição de seus acervos. O artigo traz como objeto de estudo o Museu Regional dos Inhamuns, no Ceará, e o Museu Couros de Formosa, em Goiás, correlacionados dentro de um recorte temporal a partir da instituição de seus respectivos espaços museológicos na década de 1990.

Referente à metodologia de história comparada aplicada ao campo da escrita da história nos museus, percebemos como a cultura material foi selecionada e salvaguardada como "relíquias do passado" e "culto à saudade". Com a identificação e afinidades de discursos que remetem a cultura popular local, cada museu estudado aqui expõe trajetórias distintas de práticas de preservação, sem deixa de apontar também algumas aproximações.

Uma contribuição teórica de especial relevância para a investigação é proposta no livro "A Escrita do Passado em Museus Históricos", da historiadora e socióloga Myriam Sepúlveda dos Santos. De acordo com a autora, podemos ver duas modalidades de linguagens museológicas que se conectam com impõem determinadas ordens interpretativas aos objetos:

\begin{abstract}
A história que se observa no MHN [Museu Histórico Nacional] das primeiras décadas é a criação de uma experiência que procura os elos entre presente e passado. Além dos objetos, o próprio discurso verbal que os acompanhava era também carismático, fragmentado e descontínuo... O MHN da década de 80 é aqui caracterizado como "museu-narrativa", aquele em que a narrativa histórica subordina à sua lógica o discurso do objeto... na atual exposição do MHN, a escrita da história está intimamente ligada a uma concepção de tempo linear e progressiva. (SANTOS, 2006, p. 21-22).
\end{abstract}

Analisando as narrativas históricas construída em torno do Museu Imperial e Museu Histórico Nacional (1922-1980), a autora identifica duas modalidades de narrativas ao longo do recorte temporal: "museus-memória" e "museus-narrativa".

A abordagem utilizada acima nos permite avançar com uma metodologia comparativa, considerando as narrativas encontradas em diferentes espaços museológicos estudados aqui: o Museu Regional dos Inhamuns e o Museu Couros de Formosa. Analisamos assim em que ponto os museus se aproximam e se distanciam das duas modalidades de narrativas elencadas acima.

Desse modo, a partir da dialética entre memória e história, evocação e síntese, visualizamos esses modelos de escrita da história nos museus em contextos institucionais distintos.

Enfatizamos ainda aqui o uso de uma História Comparada Problematizadora, concordando com o método apresentado pelo historiador José D’Assunção Barros:

trata-se de iluminar um objeto ou situação a partir de outro, mais conhecido, de modo que o espírito que aprofunda esta prática comparativa dispõe-se a fazer analogias, a identificar semelhanças e diferenças entre duas realidades, a perceber variações de um mesmo modelo" (BARROS, 2007, p.10). 
Desconfiando da naturalização das operacionalizações e usos da história, seguindo essa proposta comparativa, ampliamos a problematização do objeto ressaltando a dimensão visual das exposições museológicas.

A dimensão visual é ressaltada como uma importante ampliação de estudos de culturas materiais. Importantes contribuições faz-se nesse sentido, como a proposta assinalada pelo historiador Ulpiano Toledo Bezerra de Meneses:

A cultura material - da qual, a rigor, a cultura visual poderia ser considerada uma subcategoria - teria que ser estudada não como o conjunto de coisas e contextos materiais de que se serve o homem em sua vida social, mas como a dimensão física, empírica, sensorial, corporal, da produção/reprodução social (o uso do termo "cultura" aqui também pressuporia mediação de significados e valores) (MENESES, 2003, p. 25).

Diante disso, os registros fotográficos feitos a partir das exposições nos auxiliam na percepção de como a cultura é comunicada pela visualização de objetos, bem como numa leitura crítica desses materiais e da forma como são dispostos nos museus.

Antes, veremos a seguir uma breve contextualização da criação dos primeiros museus ditos regionais, para subsidiar a discussão sobre os museus regionais selecionados no presente artigo.

\title{
Museus Históricos Regionais e Representatividade Nacional
}

No contexto do final da década de 1960 tem-se o período da política de criação de museus regionais, incentivados pelas resoluções do "Compromisso de Brasília", firmado em 1970 num encontro de governadores, secretários estaduais, prefeitos e representantes de instituições culturais.

A historiadora Janice Gonçalves analisa a historicidade das resoluções de educação patrimonial tomando como base tais recomendações e experiencias contidas em documentos, tais como o compromisso de Brasília:

\begin{abstract}
Nele foi destacado o "o culto ao passado [como] elemento básico da consciência nacional”, por essa razão devendo ser tratadas as questões do patrimônio cultural nos currículos escolares de todos os níveis (item 9 - IPHAN, 1993, p.164); os museus regionais também deveriam documentar " a formação histórica, tendo em vista a educação cívica e o respeito da tradição" (item 12 - IPHAN, 1993, p.164). Um segundo encontro, realizado no ano seguinte, em Salvador, ratificou o Compromisso de Brasília (Compromisso de Salvador - IPHAN, 1993, p. 171) e, consequentemente, o culto ao passado e o respeito à tradição como referências do campo patrimonial, interpretáveis nos termos da ditadura civil-militar (GONÇALVES, 2014, p.87)
\end{abstract}

Referencias como estas citadas acima nos apontam a função social e educativa dos museus regionais como formadora de uma consciência cívica a partir do prestígio da tradição.

Lygia Martins Costa, museóloga e especialista em história da arte e que trabalhou no Instituto do Patrimônio Histórico e Artístico Nacional-IPHAN, a partir dos "Anais do II Encontro de Governadores para a Defesa de Nosso Patrimônio", ocorrido na Bahia em outubro de 1971, recomenda a criação de museus regionais aproveitando edifícios históricos como lugar que

reflete diferentes realidades locais, traz em si uma carga que o liga à gente da terra, as suas tradições, seu modo de ser. E as comunidades, a verem reunidas e 
articuladas esses remanescentes familiares, passam a compreender o processo de sua própria civilização (COSTA, 2002, p.29).

Com a proposta de criação de museus regionais, pretende-se alcançar significações culturais que representam um valor histórico regional ligados as tradições e a um "modo e ser" local.

Os museus regionais podem ser, também, uma continuação daqueles museus ditos regionais consagrados pelo Iphan, criados entre 1938 a 1958: o Museu da Inconfidência (1944); Museu do Ouro (1946); Museu do Diamante (1954); Museu Regional São João Del Rei (1958) - ambos em Minas Gerais -; e Museu das Missões (1940) - no Rio Grande do Sul. Tais museus, seja pela ditos regionais surgem com os trabalhos de preservação do patrimônio cultural no país, a partir do decreto-lei $\mathrm{n}^{\circ} 25$, de 30 de novembro de 1937, criando o Serviço de Patrimônio Histórico e Artístico NacionalSPHAN, hoje chamado Instituto do Patrimônio Histórico e Artístico Nacional-IPHAN.

Pela letra do Decreto Lei 25/37, os critérios para a seleção de um bem cultural como patrimônio nacional é estruturado sob a lógica da atribuição de valor histórico ligado à "memorabilidade" dos fatos históricos nacionais e à "excepcionalidade" arqueológica, etnográfico, bibliográfico e artístico.

Tudo indica que os museus regionais criados pelo Iphan se situam numa atribuição de valor considerado como matrizes exemplares da fundação do Brasil. O apreço pelas cidades históricas mineiras constitui a valorização de uma determinada concepção de história que via no século XVIII e no barroco a genuína tradição brasileira, "objetivada em situações estéticas concretas coo arquitetura e escultura e em fatos históricos contundentes como a Inconfidência mineira" (VELOSO, 2018, p.111).

A museóloga Letícia Julião, ao estudar a cultura museológica do Serviço de Patrimônio Histórico e Artístico Nacional-SPHAN (atualmente Instituto do Patrimônio Histórico e Artístico Nacional-IPHAN) destaca que a proposta educacional dos museus aponta para critérios de valorização não apenas aos fatos memoráveis da história do Brasil, mas também ao valor histórico expressivos dos diversos elementos que constituíram a população brasileira e característicos das etapas principais do desenvolvimento civilizacional do Brasil:

Tratava-se de assegurar uma narrativa cuja lógica era definida a partir de parâmetros civilizacionais ou estéticos previamente definidos pelo corpo técnico do Sphan, e para os quais pouco importava a procedência familiar ou social dos acervos. Ainda que os critérios colecionistas recaíssem sobre objetos oriundos do universo material das elites, não se tratava mais de consagrar pessoas ou fatos isolados, orientação diametralmente oposta àquela que irá marcar grande parte dos museus históricos, com destaque para o Museu Histórico Nacional. (JULIÃO, 2009, p.153).

Dialogando com uma determinada prática antiquaria se fizesse presente, a orientação de criação de museus relaciona-se com a construção de uma identidade nacional e a consagração de uma memória de representantes das elites consubstanciadas em coleções.

Assim, conhecer o Brasil era debruçar-se sobre a marcha civilizacional, didaticamente atrelada aos ciclos econômicos os vestígios da cultura material largados no tempo: engenhos, igrejas, fortes, armazéns velhos, casas rurais, câmaras e fazendas de café, cidades, peças artesanais etc. 


\section{Museografias da Cultura Material}

As salas que compõem o acervo material do Museu Regional dos Inhamuns e o Museus Couros de Formosa documentam fortemente um aspecto histórico da conquista e colonização do interior do Brasil: o processo de ocupação pela instalação de fazendas de gado. $O$ centro de interesse dessas exposições reside sobretudo na figura de construtores de uma civilização típica - a civilização do boi ou, na linguagem de Capistrano de Abreu, a Civilização do Couro.

O surgimento de vilas e cidades situa-se em pontos de travessia que se interligavam por todo o sertão e serviam de hospedagem para os passadores de gado que iam abastecer o interior e comercializar charque e couro.

No tópico denominado "Sertões", no livro "Capítulos de História Colonial” do historiador Capistrano de Abreu, foi narrada um modo de viver de uma sociedade que se fez a partir de uso de uma determinada cultura material adaptada aos elementos do meio geográfico:

[...] de couro era a porta das cabanas, o rude leito aplicado ao chão duro, e mais tarde a cama para os pastos; de couro todas as cordas, a borracha para carregar água, o mocó ou alforje para levar comida, a maca para guardar roupa, a mochila para milhar o cavalo, a peia para prendê-lo em viagem, as bainhas da faca, as broacas e surrões, a roupa de entrar no mato, os banguês para o curtume ou para apurar o sal; para os açudes, o material de aterro era levado em couro puxado por juntas de bois que calcavam a terra com seu peso; em couro pesava-se tabaco para o nariz (ABREU, 1969, p.162).

A identificação de bens culturais no território compreendido entre os sertões cearense e centro-oeste goiano, pelo processo de urbanização advinda com a instalação das primeiras fazendas de gado no final do século XVII e início do século XVIII, implica assim numa forma de representação histórica cultural.

A cultura material da civilização do couro nesses museus é o mote historiográfico que guia o visitante a uma visão do passado em torno do sertão: arte sacra, objetos domésticos, utensílios do trabalho no campo, artesanatos, quadros pictóricos, moedas, fardas militares, armas de fogo, punhais, facões, fotografias em preto e branco, exemplares de carros puxados a boi, cadeiras, mesas etc.

Tais objetos se aproximam conceitualmente daquilo que Sepúlveda (2006) denominou de "relíquias do passado", um

'culto da saudade' que representou a tentativa de consolidar uma tradição nacional por meio de objetos que, por serem valorizados como autênticos fragmentos do passado, funcionavam como símbolos poderosos dos "heróis" eleitos por uma elite dominante (SANTOS, 2006, p.41).

Percebendo a matriz historiográfica subjacente aos museus selecionados, passamos agora à análise dos registros recolhidos nos dois espaços museológicos e seus respectivos acervos: o Museu Regional do Inhamuns e o Museu Couros de Formosa.

\section{O Museu Regional dos Inhamuns, Município de Tauá, Estado do Ceará}

O Museu Regional dos Inhamuns foi instituído oficialmente no dia 02 de fevereiro de 1992, no município de Tauá, zona norte do estado do Ceará. O museu foi instalado no edifício da antiga Casa de Câmara e Cadeia de Tauá, fundada em 06 de janeiro de 1903, e que foi tombado pelo conselho municipal de preservação do patrimônio cultural de Tauá em 10 de abril de 2006. 
Situado na região conhecida como Sertão dos Inhamuns, o museu é abrigado pela fundação Bernardo Feitosa, que reúne peças e mobiliário que pertenceram a Joaquim de Castro Feitosa e sua esposa Maria Dolores de Andrade Feitosa, descendentes da tradicional família Feitosa que se estabeleceu na região no período colonial. Joaquim Feitosa e sua esposa se empenharam em colecionar peças que contassem a história da família no semiárido cearense, como bem fala a senhora Maria Dolores Fetosa:

\begin{abstract}
$\mathrm{O}$ museu tem em suas origens características muito especiais. Na verdade, ele não foi fundado: "nasceu" da integração de duas fortes famílias de tradições fortes, oriundas de Tauá e de Sobral, que uniram seu destino através do nosso casamento. Acontece que, além dos sonhos e planos de todo jovem casal, nós dois tínhamos a esma determinação de dar prosseguimento às tradições de nossas famílias e à busca, conservação e preservação de objetos que representavam essas tradições. (MUSEU REGIONAL DOS INHAMUNS, 2015, s.n.p)
\end{abstract}

É forte a centralidade da família Feitosa na concepção, catalogação e preservação do acervo, que acaba por se confundir com a própria história do município, uma vez que os objetos ali salvaguardados representam como sendo uma herança familiar ao interesse público e cívico.

A importância da família Feitosa deu-se devido às atividades pecuaristas, construindo uma sólida influência na região pela agricultura. A família Feitosa constituiu-se de numerosos vaqueiros e agregados oriundos da região. A região dos Inhamuns é chamada de "País dos Vaqueiros" num artigo publicado junto ao Instituto Histórico e Antropológico do Ceará:

Lendo-o vivi um pouco da minha juventude, relembrei um passado que não vai longe mas que se entrosa com os fatos antigos, porque desde criança aprendi a amar extremosamente a mina terra ouvindo os feitos heroicos de seus destemerosos vaqueiros" (FREITAS, 1965, P.328).

Inspirado em reminiscências juvenis, o autor escreve a memória dos antigos desbravadores dos sertões, considerados feitos heroicos de um drama histórico que alicerçou as bases civilizacionais.

A cultura vaqueana assim se faz presente no museu com diversos objetos referentes ao ofício de vaqueiro, bem como utensílios que relatam o modo de vida rural daquelas paragens.

Imagem 1 - Selas e Indumentária Típica do Vaqueiro

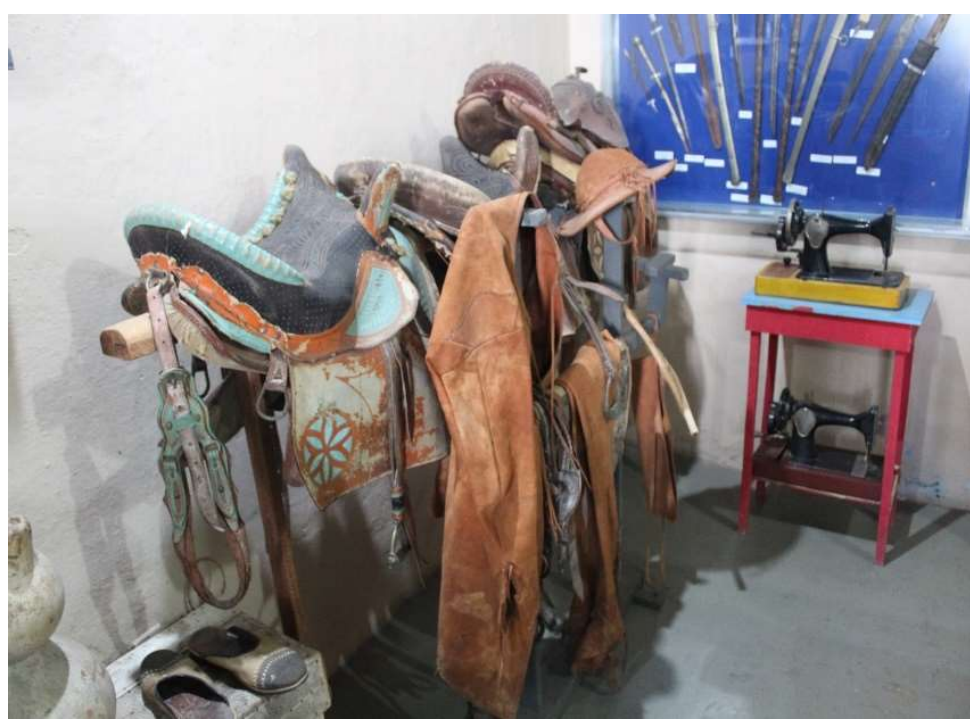

Fonte: O Autor, 2020. 
Do amontoado de vestimentas de couro, bem como a máquina de costura, vemos acima vestígios de um passado que corrobora com a memória construída pela família Feitosa, perpetuada no museu sob a civilização do couro. Tal memória é acessada por quem visita o museu como um templo ancestral.

A busca pela ancestralidade fez o acervo do museu aumentar, com as viagens de Joaquim Feitosa pelo sertão cearense, adquirindo objetos que considerava autêntico, exemplificado no termo de doação assinado abaixo por Veridiano Alexandre Filho em memória de seu pai:

Estou doando ao Museu Regional dos Inhamuns um par de estribos que o mesmo usava em suas cavalgadas pelas fazendas; Cedro, Cajazeiras, Cachoeirinha, Catirina, Feijão, São Félix, Central, Machado, Oiticica, Lagamar, Santa Luzia, Volta, Mato Grosso, Trapiá, Santa Maria e Vaca Brava. (MUSEU REGIONAL DOS INHAMUNS, 2007, s.n.p).

Os estribos doados são autênticos por pertencerem a famílias oriundas da ocupação e colonização pela instalação de fazendas de gado. Tais objetos são doados e catalogados como relíquias do passado.

Imagem 2 - Estribos.

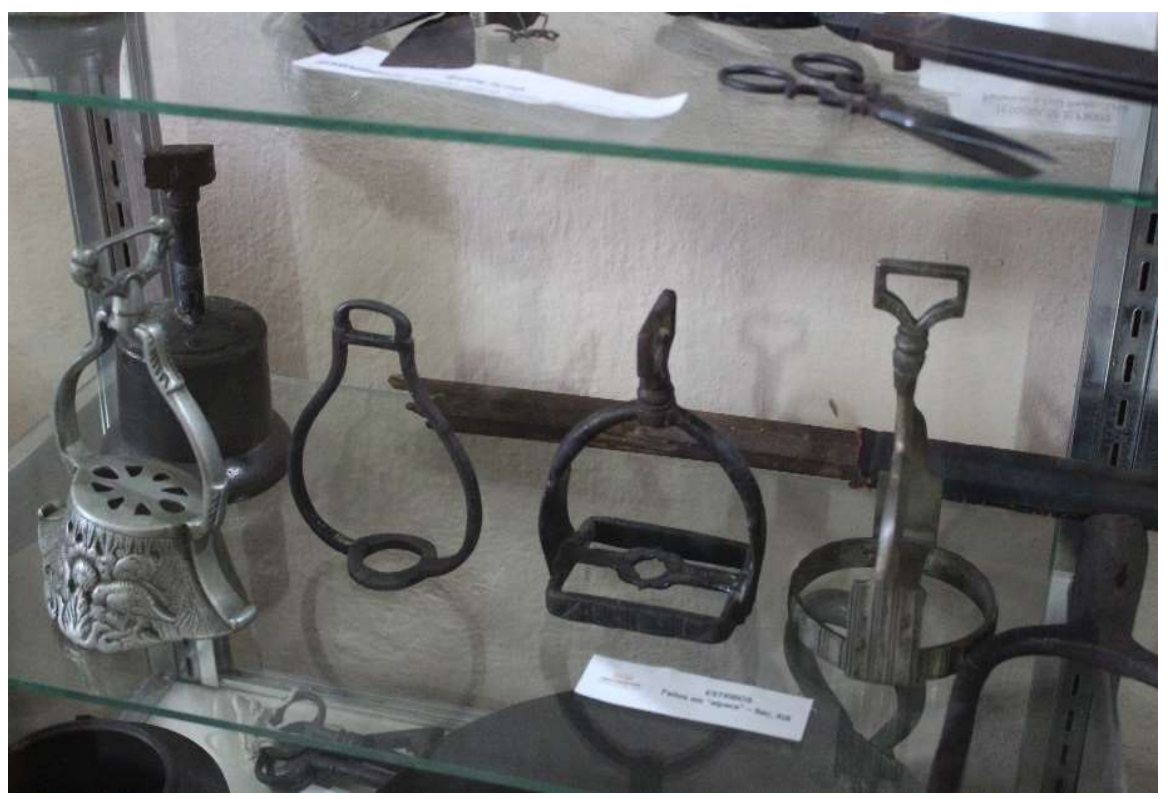

Fonte: O Autor, 2020.

Os estribos acima encarnam exemplarmente a cultura o personagem típico da civilização sertaneja em sua atividade mais cotidiana, investigada nos mais íntimos detalhes de seu ofício. Espelhando esse cotidiano doméstico do sertão, são catalogados diversos objetos típicos dos afazeres do lar e da intimidade, como vemos abaixo os lampiões, lamparinas, potes de barro, castiçais, ferros de passar roupa e até uma coleção de armadores de rede para dormir. 
Imagem 3 - Utensílios Domésticos Sertanejos

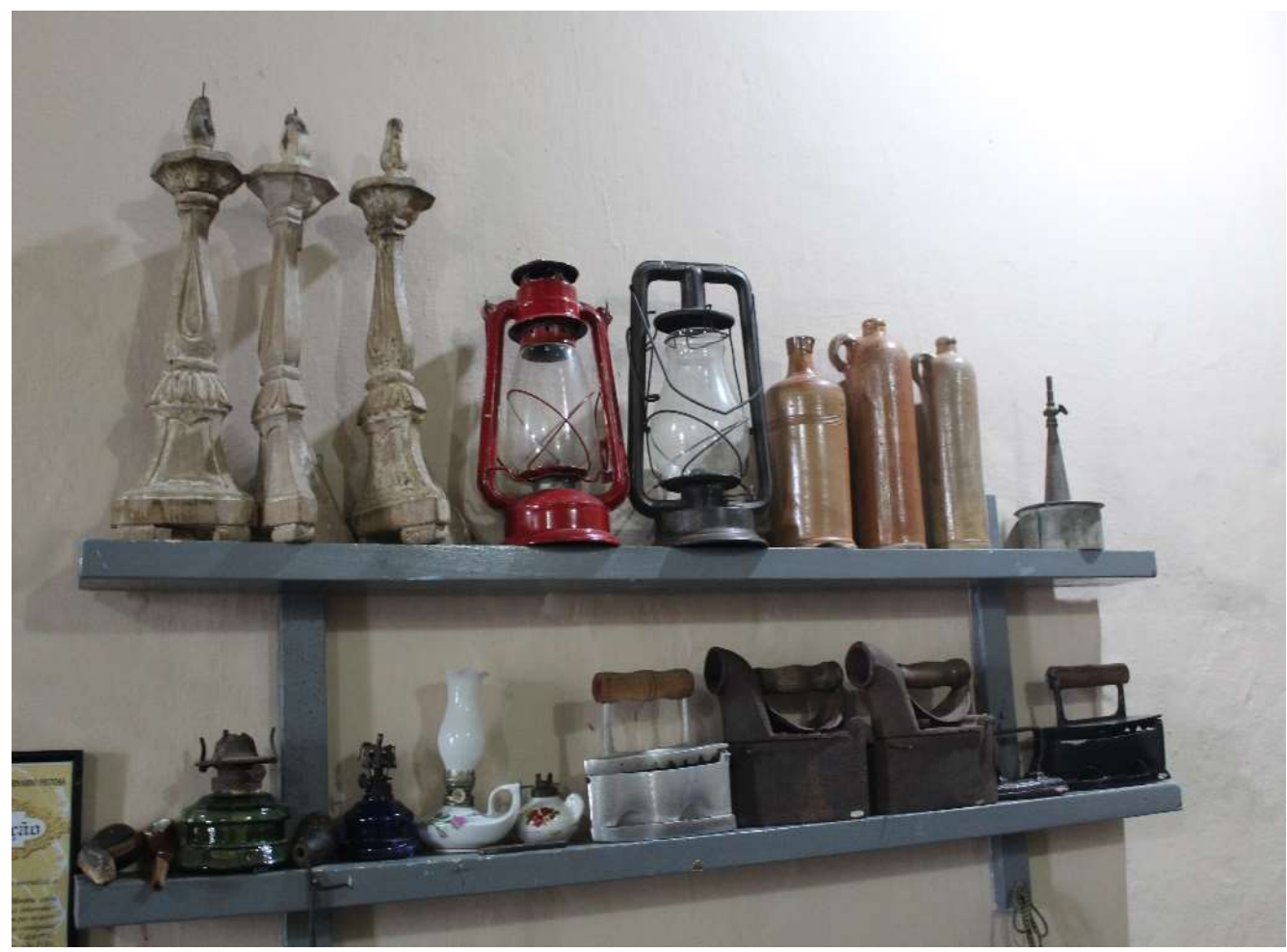

Fonte: O Autor, 2020.

Imagem 4 - Coleção de Armadores de Redes de Dormir

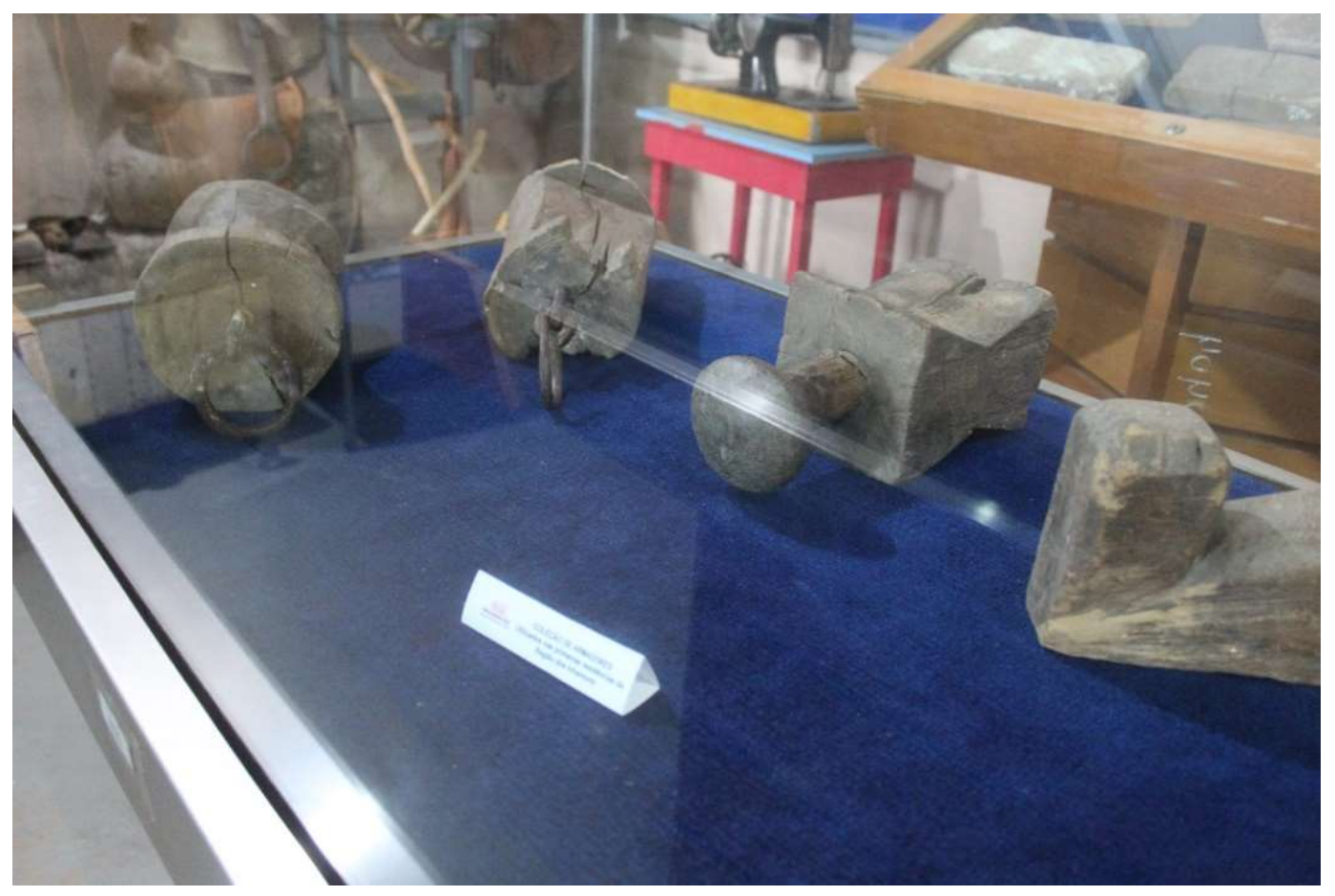

Fonte: O Autor, 2020.

O interesse em catalogar os modos de vida na região dos Inhamuns abrange uma concepção etnográfica elencada também numa concepção histórica evolutiva. O museu encontra-se também salvaguardados vestígios dos primeiros habitantes da região. Abaixo vemos fragmentos arqueológicos de cerâmicas nativas: 
Imagem 5 - Fragmentos de Cerâmicas Indígenas

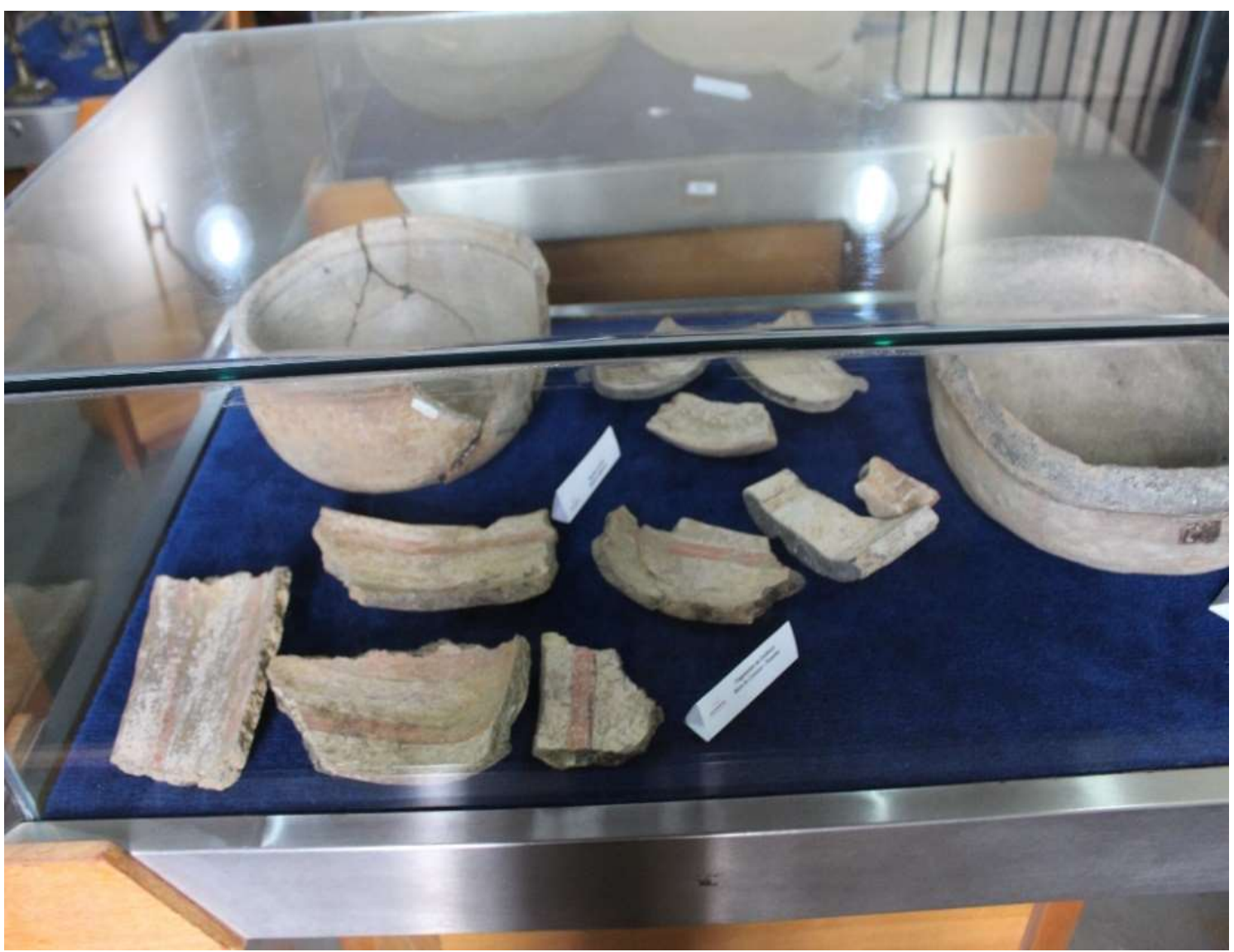

Fonte: O Autor, 2020.

Contando assim com um importante acervo arqueológico e paleontológico (este identificado num dos sítios paleontológicos da região, o Caldeirão II), as exposições dos objetos sintetizam uma parte da formação socioeconômica e cultural da região dos Inhamuns.

A forma como os objetos são dispostos no museu remete à concepção de artefatos que contam as origens do processo de ocupação do território. Os objetos são expostos conforme critérios que dizem respeito à própria denominação de sua função e usos destes no passado.

Tais objetos são expostos, assim, como uma função evocativa de memória coletiva, onde os objetos "aurificados" falam por si, sendo testemunhos silenciosos de uma epopeia civilizatória.

\section{Museu Couros de Formosa, Município de Formosa, Estado de Goiás}

O Museu Couros de Formosa foi instituído oficialmente no dia 26 de abril de 1996, no município de Formosa, estado de Goiás. A Fundação Museu Couros de Formosa situase hoje num antigo casarão onde outrora tinha funcionado a área de exposição dos animais, depois Associação Rural de Formosa destinado a construção do Parque Permanente de Exposição de Animais e organização da exposição de produtos do município. 
Após um longo trabalho de catalogação, inventário e escrituração pública do acervo, foi então criada a Fundação Museu Couros de Formosa-FUMUC. O museu e seu acervo começaram a ser montado e catalogado por um grupo de jovens amigos liderados na época pelo jovem Leônidas da Silva Pires. Quem narra essa trajetória é o próprio Leônidas da Silva Pires, conhecido popularmente como Leo, num artigo assinado pelo mesmo, intitulado "História do Museu dos Couros". ${ }^{1}$

Com a finalidade de divulgar e incentivar a arte e a cultura local, Léo começou a "garimpar" pelas ruas da cidade, visitando famílias tradicionais no sentido de conseguir objetos que ajudasse a contar a história de Formosa.

O museu assim é concebido por jovens idealistas que buscaram no conhecimento histórico local um projeto cultural que desse vazão aos seus anseios. Tai jovens "beberam" da tradição intelectual dos "homens de letras", que tinham uma concepção de cultura como "cultivo" do espírito. Para isso, incorreram nas veredas do passado buscando documentos da história local, empreendendo um esforço de resgate dos vestígios materiais.

Aqui cabe o conceito de "trabalho de enquadramento de memórias" formulado por Michael Pollak (1992), na qual este analisa sobre a identidade social como uma estruturação de memórias, organizada em função das preocupações pessoais e políticas, sendo "perfeitamente possível que, por meio da socialização política, ou da socialização histórica, ocorra um fenômeno de projeção ou de identificação com determinado passado, tão forte que podemos falar numa memória quase que herdada (POLLAK, 1992, p.2).

Os investimentos do passado alavancam uma memória herdada utilizada como ponto de origem do passado e projeção continuada para o futuro: a memória do pioneirismo das tropas e boiadas, dos estabelecimentos de fazendas de criação de gado.

O nome Museu Couros de Formosa remete ao período de povoamento do Arraial dos Couros, antigo nome de Formosa, que segundo moradores, deu-se à estalagem de tropeiros e comerciantes que vendiam peles de animais desde meados do século XVIII. Abaixo vemos alguns objetos trabalhados em couro pertencentes ao acervo.

\footnotetext{
1 Ver: http://formosadaimperatriz.blogspot.com/2019/06/1986-museu-dos-couros-de-formosa.htm]
} 
Imagem 6 - Utensílios de Couro.

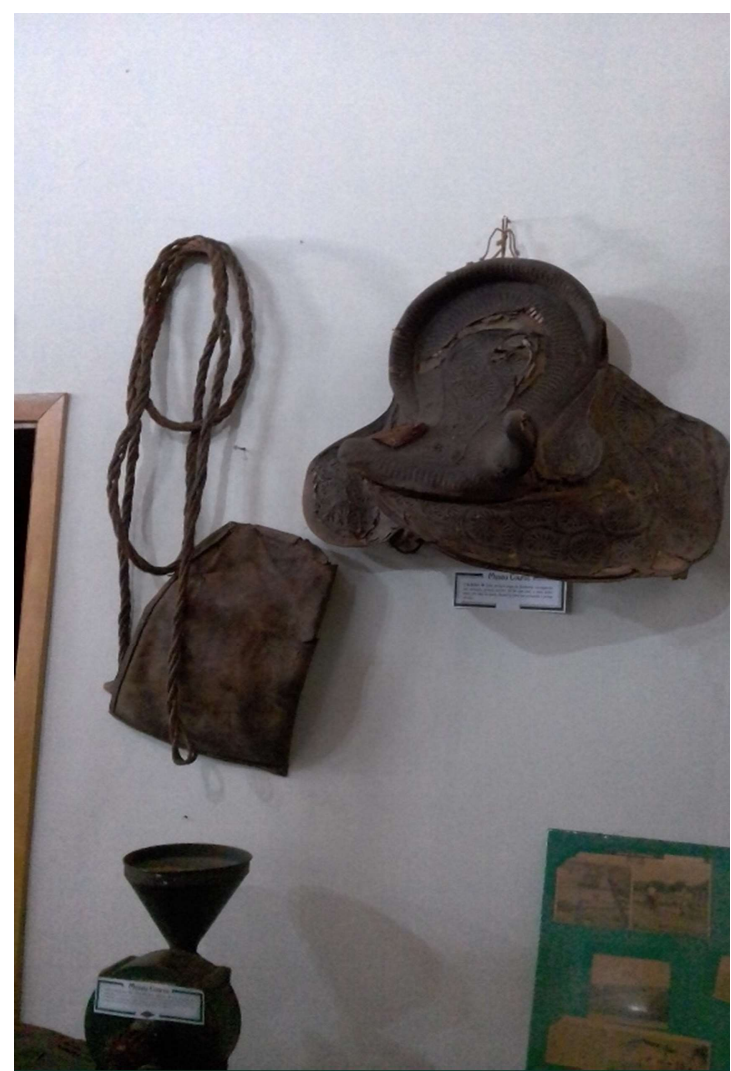

Fonte: O Autor, 2019.

Imagem 7 - Cadeira Revestida de Couro

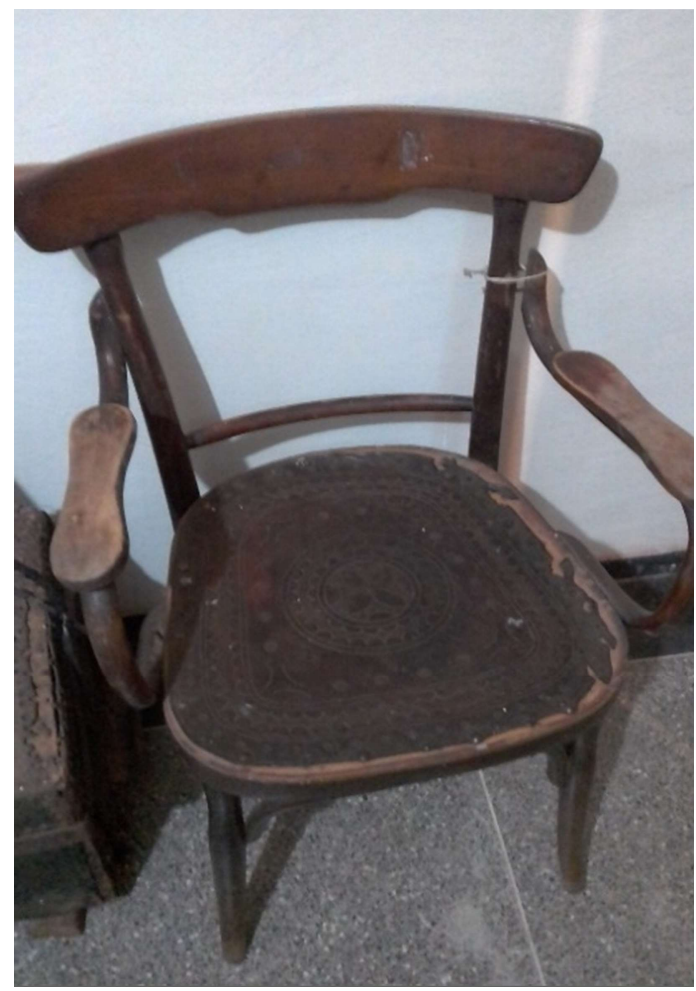

Fonte: O Autor, 2019.

Tais objetos de couro remete às origens da gente formadora do núcleo urbano: tropeiros, tangerinos e vaqueiros. Artefatos históricos de couro simboliza a própria 
gênese do Museu, baseado no resgate de memórias a partir da cultura material. Importante salientar que esses objetos de couro remetem também ao cotidiano do trabalho rural, principalmente no plantio e cultivo de pequenas roças.

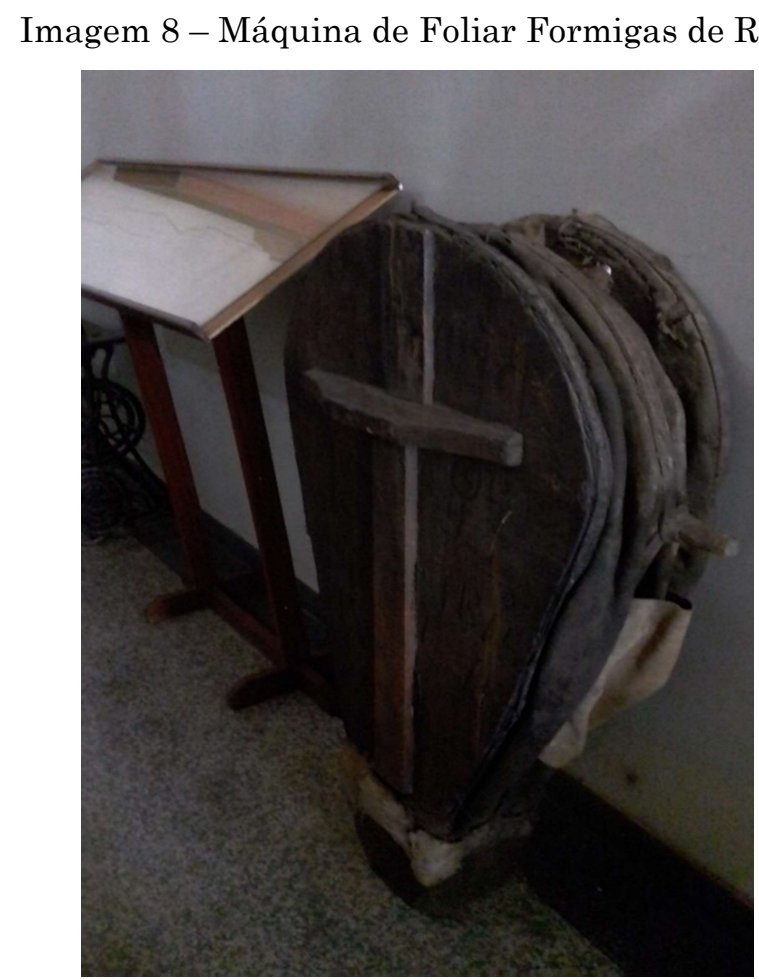

Fonte: O Autor, 2019.

O romance regionalista goiano é farto de descrições de costumes e cultura material das populações dos sertões gerais e chapadões do planalto central, que nos apontam aproximações com a concepção de museu regional aqui analisado:

À tarde, o eco dum aboiado rolou pelo fundo da várzea, ondulando dolentemente de quebrada em quebrada, num despertar intenso de saudade... eram boiadeiros que lá passavam, na estrada batida. $O$ vaqueiro velho não saiu então como de costume, ferrão em punho, perneiras e guarda-peito, escorreito e desempenado, no rosilho campeador, a dar a mão de ajuda àqueles forasteiros que lá iam, demandas de terras distantes e das feiras ruidosas dos sertões mineiros d'além Paranaíba (RAMOS, 1998, p.16).

Como descrito em contos pelo escritor Hugo de Carvalho Ramos, citado acima num pequeno trecho, a ideia central do museu é relembrar os costumes e a cultura material, preservando a tradição. Daí veio a ideia de realizar eventos para promover parte das tradições e também gerar renda a partir de feiras de práticas de fiar algodão e moer mandioca. 
Imagem 9 - Máquina de Fiar Algodão

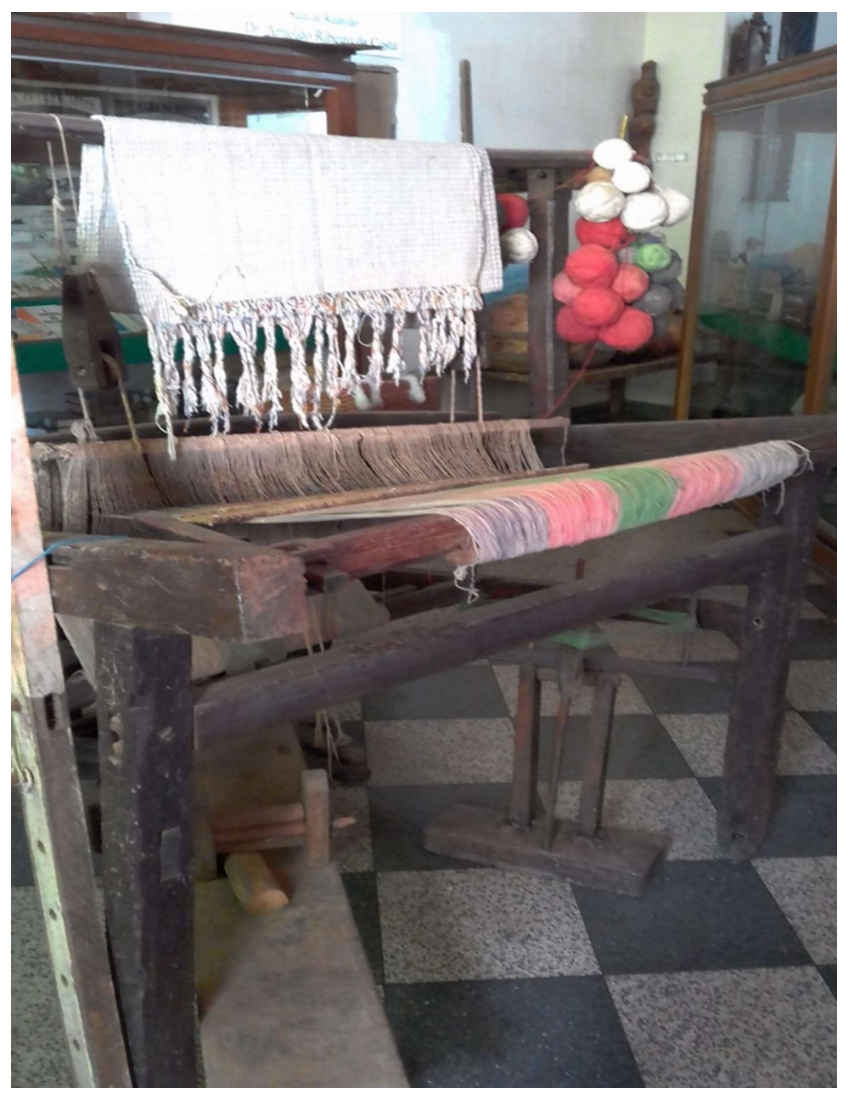

Fonte: O Autor, 2019.

Imagem 10 - Pilão de Madeira

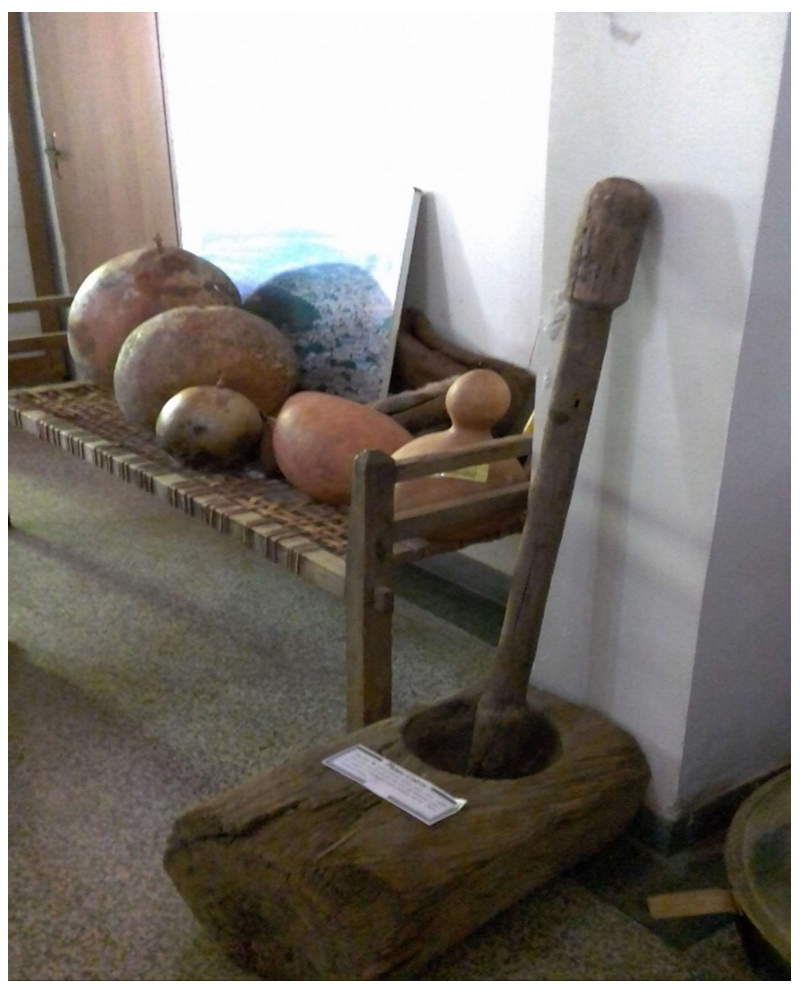

Fonte: O Autor, 2019. 
Os objetos acima servem assim como referência histórica para a preservação da memória de um saber-fazer popular. Tais objetos evocam a memória que se estabelece no presente, em eventos do calendário local e cotidiano da própria comunidade. Assim, para manter o museu aberto e próximo à comunidade, Leônidas Pires e voluntários organizam eventos ao longo do ano, como o exemplo abaixo:

Realizada sempre em junho, há 14 anos, a Feira da Moagem mostra aos
visitantes como era a produção artesanal de alimentos na região nos séculos 18
e 19. Entre outras atrações, fiandeiras vão transformando o algodão em tecido,
um trabalho centenário que requer muita habilidade nas mãos e nos pés. A partir
da mandioca, mostra-se o processo de feitura de farinha, beiju, goma e puba.
Garapa, melão, rapadura, batida, puxa-puxa, açúcar mascavo e pinga também
já têm espaço cativo no evento (ALVES, 2012, s.n.p).

Com o objetivo de não apenas retratar fielmente a cultura material, o museu transpõe a dimensão visual dos objetos e retroalimenta um espaço com usos contemporâneos do passado.

\section{Análise Comparativa Entre os Museus}

Vimos que as instituições museais produzem uma narrativa com os objetos e constroem memórias com eles. A análise crítica dessas narrativas e memórias pressupõe pensarmos em combinações metodológicas de leituras dos objetos e da forma como são dispostos nos museus.

Além disso, a análise crítica dos documentos perpassa pela questão dos usos sociais do passado. Os museus regionais aqui estudados tem em sua concepção a definição do patrimônio e identidade como reflexo fiel da essência nacional/regional. Assim define "o porvir do passado" Nestor Garcia Canclini (1998), ressaltando o fundamento filosófico do tradicionalismo baseado "na certeza de que há uma coincidência ontológica entre realidade e representação, entre sociedade e as coleções de símbolos que a representam (CANCLINI, 1998, p.163). Esse aspecto tradicionalista é consubstanciado aqui nas representações museais e suas respetivas trajetórias.

Em contextos museológicos distintos, percebemos a permanência do discurso de "museu-memória", centrado na exposição dos objetos que falam por si, sem uma síntese histórica encadeadora dos processos históricos.

A concepção de documentos históricos investigados nos museus se aproxima do método historicista do século XIX pela atribuição de valor histórico como "testemunhos" da formação sociocultural do povo brasileiro e dos diversos elementos que o constituem. Os museus históricos regionais baseiam-se assim pela ideia da autenticidade dos documentos históricos "como eles realmente aconteceriam", ou seja, em busca de uma verdade histórica encrustada nos vestígios materiais.

O critério de seleção dos objetos dos museus regionais analisados aqui justificase a partir de ordenamento sistemático de visualização do passado exemplar. A rusticidade por trás desses objetos traz à tona o telurismo como singularidade. A saudade é a marca que traz a autenticidade dos objetos, que tem como finalidade celebrar o passado de seus antepassados, como forma de garantir um sentimento de unidade identitária.

Práticas de perpetuação do passado, seja como lugar de consagração do legado de famílias das elites locais, seja como lugar de consagração da gênese histórica, são formas de escrita patrimonial. A partir dos registros realizados do acervo material dos museus 
regionais que fazem referências ao pensamento do processo civilizatório brasileiro pautado no desenvolvimento da civilização material no Brasil ${ }^{2}$, as exposições museológicas denotam uma elaboração da preservação da memória como depositário de valores morais transmitidos a partir da epopeia da conquista e criação de uma civilização.

Nas salas, vemos uma ênfase na temática do ciclo econômico do gado subjacente ao processo de urbanização nos sertões. Vestígios desse legado histórico são os objetos oriundos do cotidiano rural e do ofício do vaqueiro, principalmente suas vestimentas e acessórios de trabalho nas fazendas. Aliado a isso, percebemos também como o agenciamento da causa patrimonial arregimenta em torno de si diferentes formas de visualização do passado.

Aqui, "não se trata de pensar numa evolução das formas de escrita patrimonial, mas antes de pensar nas diferentes maneiras sob as quais esses restos materiais do passado vieram a ser tratados sob a forma de patrimônio histórico." (GUIMARÃES, 2011, p.97). Podemos assim perceber alguns distanciamentos e aproximações entre os dois museus pesquisados.

Sob o aspecto de uma tradição familiar ligada aos primeiros colonizadores, identificados na figura regional do vaqueiro, o Museu Regional dos Inhamuns se constituiu a partir de uma ação de perpetuação de uma memória ligada a uma família ancestral e guardiã dos objetos, que com o museu, esta ganhou forma de tradição regional com a cultura vaqueira. A coleta e catalogação para a organização do acervo partiu do esforço de práticas de "antiquarismo" e de colecionamento de objetos familiares tidos como documentos históricos relíquias do passado heroico.

A investigação da exposição dos objetos no Museu Regional dos Inhamuns nos remete também, implicitamente, a uma concepção histórica e etnográfica que procura datar os objetos numa linha evolutiva, inscrevendo os vestígios arqueológicos e paleontológicos na linha do tempo, fechando assim o arco temporal do desenvolvimento material da região. Aqui não vemos muto da cultura étnica dos povos indígenas habitantes da região, quando muito, artefatos expostos como um passado remoto e distante do presente.

Já a constituição do acervo e exposição do Museu Couros de Formosa partiu de um interesse coletivo pelo resgate da memória dos elementos materiais constituintes da fundação da cidade de Formosa. Fruto de doações de antigos moradores de fazendas, os objetos trazem a marca de autenticidade, por carregar em si a memória dos costumes dos tempos de outrora. A busca pela autenticidade da cultura material de Formosa orientou a ação intelectual de construção de um projeto cultural que tem como concepção de cultura o "cultivo" do espírito.

Vemos no Museu Couros de Formosa uma marca fortemente ligada ao resgate da cultura material e sua perpetuação não só na salvaguarda do museu, mas também na prática coletiva de perpetuação e continuidade dos costumes de trabalhos e lazer dos tempos de outrora.

\footnotetext{
2 Importante salientar que a concepção de Cultura que presidiu a criação do IPHAN é a noção de civilização como controle da natureza pela técnica, que substancia o progresso da civilização material no Brasil, como atesta o livro Desenvolvimento da Civilização Material no Brasil, de Afonso Arinos de Melo Franco, Resultado de cinco palestras proferidas em 1938, a fim de treinar o pessoal técnico recémcontratado pelo SPHAN, à pedido de Rodrigo Melo Franco de Andrade, que queria que seus técnicoş61 tomassem conhecimento do desenvolvimento da cultura material do país.
} 
Em ambos os museus analisados, é notório como a história é a mestra da vida, onde a memória coletiva trabalha através de seus detentores, efetuando um trabalho de manutenção, de coerência, de unidade, de continuidade, de organização e de serviço público.

\section{Encaminhamentos Conclusivos}

Vimos aqui que a categoria de museu de museu histórico regional operacionaliza uma determinada escrita da história pautada em narrativas cuja lógica é definida a partir de parâmetros civilizacionais, ou seja, no processo histórico de conquista, colonização e urbanização do interior do Brasil. Conhecer e preservar os vestígios materiais desse processo histórico foi condição seminal para o culto ao passado como elemento básico da consciência nacional e para a formação histórica, tendo em vista a educação cívica e o respeito da tradição.

Pelo recorte territorial e temporal da pesquisa, vimos como a cultura popular relacionada aos costumes da gente goiana e cearense foram espelhados pelo Museu Couros de Formosa e Museu Regional dos Inhamuns respetivamente, a partir da constituição, catalogação e exposição de objetos oriundos da convivência das populações com a natureza de cada região.

Esses museus se inserem numa problemática de construção social da memória, em termos de investimentos de identidades coletivas. Seguimos a concepção de identidade social de Pollak: "investimentos que um grupo deve fazer ao longo do tempo, todo o trabalho necessário para dar a cada membro do grupo - quer se trate de família ou de nação - o sentimento de unidade, de continuidade e de coerência" (POLLAK, 1992, p.7). Assim, vimos como a história (como narrativa museográfica de atribuição de valor de patrimônio) subsidiou identidades sociais.

Pela metodologia de pesquisa histórica comparada, identificamos trajetórias e museografias que se utilizaram de procedimentos metodológicos para a produção de conhecimentos sobre o patrimônio cultural relacionado a museus históricos regionais.

Ambos os museus históricos analisados aqui conformam características de "museus-memórias", cuja conhecimento e identificação histórica reside na centralidade afetiva dos objetos, condicionada pela dimensão visual das salas expositivas. No entanto, pela trajetória da constituição desses museus, identificamos agenciamentos, composições e organização de acervos distintos a partir de diferentes agenciamentos de memórias por parte de agentes de políticos locais, servidores públicos e grupos sociais interessados na causa da preservação do patrimônio cultural e da legitimação e construção identitária.

Em suma, as tradições são colocadas em espaços museológicos em exposição para legitimação daqueles grupos hegemônicos que se apropriam delas como "origem”.

Os resultados do persente artigo busca ressaltar propostas metodológicas de investigação de atribuição de valor históricos em museus, a partir de seus acervos. A metodologia de pesquisa comparada nos ajuda assim a perceber como a história e a memória são requisitadas de formas distintas, bem como nos ajuda a pensar na questão dos usos sociais do patrimônio no presente.

A pesquisa também aponta para compreensões de elaborações sentidos e usos do passado na contemporaneidade, analisando as paisagens patrimoniais que nos dividem, nos cercam, nos definem, e que vem habitar a nossa própria subjetividade. 


\section{Referências}

ABREU, Capistrano de. Capítulos de História Colonial (1500-1800) \& Os Caminhos Antigos e o Povoamento do Brasil. 5a . Ed, Brasília., UnB, 1963.

ALVES, Renato. Conhecida pela Pecuária, Formosa teve suas Primeiras Fazendas no Século 18. Correio Braziliense, Brasília, 06 jan. 2012, atualizado em 26 jan. 2012. Disponível em: https://www.correiobraziliense.com.br/app/noticia/cidades/2012/01/26/interna cidadesd f,287616/conhecida-pela-pecuaria-formosa-teve-suas-primeiras-fazendas-no-seculo18.shtml

BARROS, José D'Assunção. História Comparada - da contribuição de Marc Bloch à constituição de um moderno campo historiográfico. HISTÓRIA SOCIAL. Campinas, $\mathrm{n}^{\circ}$ 13, 2007.

CANCLINI, Néstor García. Culturas Híbridas: estratégias para entrar $e$ sair da modernidade. São Paulo: Edusp, 1998.

COSTA, Lygia Martins. De Museologia Arte e Políticas de Patrimônio. Rio de Janeiro: IPHAN, 2002.

FREITAS, Gomes de. No País dos Vaqueiros. Revista do Instituto do Ceará. Fortaleza, ano LXXIX, 1965.

GONÇALVES, Janice. Da Educação do Público à Participação Cidadã: sobre ações educativas e patrimônio cultural. MOUSEION (UNILASALLE). Canoas, v. 19, p. 83-97, 2014.

GUIMARÃES, Manuel Luis Salgado. História, Memória e Patrimônio. Revista do Patrimônio Histórico e Artístico Nacional. Brasília, nº 34 / 2012.

JULIÃO, Letícia. O Sphan e a Cultura Museológica no Brasil. Estudos Históricos. Rio de Janeiro, vol. 22, nº 43, janeiro-junho de 2009, p. 141-161.

MENESES, Ulpiano T. Bezerra de. Fontes visuais, cultura visual, história visual: balanço provisório, propostas cautelares. Rev. Bras. Hist.[online]. 2003, vol.23, n.45, pp.11-36.

MUSEU REGIONAL DOS INHAMUNS. Fundação Bernardo Feitosa. Fortaleza, Expressão Gráfica e Editora, mar. 2015.

MUSEU REGIONAL DOS INHAMUNS. Termo de Doação. Tauá-CE. Ago. 2007.

POLLAK, Michael. Memória e Identidade Social. Estudos Históricos, Rio de Janeiro, vol. 5, n. 10, 1992, p. 200-212.

RAMOS, Hugo de Carvalho. Tropas e Boiadas. Fortaleza: Diário do Nordeste/Editora Verdes Mares Ltda, 1998.

SANTOS, Myrian Sepúlveda dos. A Escrita do Passado em Museus Históricos. Rio de Janeiro: Garamond; Minc/IPHAN/DEMU, 2006.

VELOSO, Marisa. O Tecido do Tempo: o patrimônio cultural no Brasil e a Academia Sphan. Brasília: Editora Universitária de Brasília, 2018. 